\title{
ACUTE CARDIAC INFARCTION WITHOUT PAIN
}

\author{
BY \\ CORNELIO PAPP \\ From the Cardiac Department of the Charing Cross Hospital \\ Received September 1, 1950
}

The precision of electrocardiographic diagnosis in cardiac infarction has shifted the interest from the clinical to the instrumental signs. Yet the diagnostic approach at the bedside remains clinical and is based on the presence of cardiac pain.

It is well known that coronary pain may be absent in the course of acute cardiac ischæmia. The incidence of coronary thrombosis without pain is difficult to assess since the selection of cases depends on the subjective appreciation of the patient and on the critical judgment of whoever takes the history. Some patients are too ill for a detailed history to be taken, in others discomfort in the chest or abdominal symptoms replace the pain; some of the published surveys include old infarctions in their material and so arrive at misleading conclusions. That explains the wide variation in incidence given as low as 2 per cent (Parkinson and Bedford, 1928) and as high as 42 per cent (Gorham and Martin, 1938); between these two extremes are the figures of 33 per cent (Boyd and Werblow, 1937) and of 4 per cent (Kennedy, 1937).

If criteria for selection are rigidly applied, acute cardiac infarction without pain is a rare event. It occurs in two distinct groups of cardiac patients: in those in whom acute coronary occlusion supervenes during cardiac failure (Parkinson and Bedford, 1928; East et al., 1928; Papp, 1934), and in those in whom complete heart block is the first sign of cardiac infarction (Master et al., 1938; Cookson, 1942). In the first group sudden increase of dyspnœa, in the second group syncope and Stokes Adams attacks, were described as the leading symptoms. All patients of the first group are severely ill and, if they survive the attack, they soon die of cardiac failure. The prognosis in the second group is equally grave and all four patients of Master et al.(1938) with complete heart block died within ten days of the attack. In Cookson's (1942) series, where syncopal attacks ushered in coronary thrombosis six out of ten patients died within four months. Exceptions are known and two out of five of Kerr's (1937) patients with complete heart block after coronary thrombosis recovered and one lived for 11 years.

In the present series out of a material of 150 cases diagnosed as coronary thrombosis with electrocardiographic signs of acute cardiac ischæmia, there were $7(4.6 \%)$ in whom pain was completely absent; in another patient (Case 6) slight pain was present for a short time only. Three out of these eight belonged to the first group with congestive heart failure; these were the ones, out of fifteen patients with pre-existent heart failure in our series, in whom acute coronary thrombosis was not accompanied by cardiac pain. Two died and one recovered. The remaining five belonged to the second group where complete heart block appeared at the onset of cardiac infarction $(3 \cdot 3 \%$ of the series). In four of these the electrocardiogram was confirmatory; complete heart block was present for one hour in Case 5, for 4 hours in Case 4, for 5 days intermittently in Case 6, and for a week or more in Case 8. In Case 7 no record was obtained during the hour while the pulse rate was 40 ; subsequent records showed normal rhythm with extensive posterolateral and possibly small anteroseptal infarction. There were no other cases with complete heart block in our material and except for Case 6 they have not experienced any cardiac pain. They all survived; Case 8 had 
a slight coronary attack 18 years later with cardiac pain and without heart block from which he also recovered.

\section{Acute Cardiac Infarction without Pain During Heart Failure (Three cases)}

The leading symptom was a sudden attack of orthopnoa with severe distress and cyanosis and with clinical and radiological signs of acute pulmonary odema. The pre-existing congestive heart failure was due in Case 1 (Fig. 1) to generalized and progressive coronary narrowing and in Case 2 (Fig. 2) to previous extensive myocardial infarction and pulmonary infarcts. Both patients were desperately ill and survived for days only. The findings at necropsy proved the extensive damage to the heart; in each patient two main coronary branches were occluded. In Case 1 the left ventricle was hypertrophied and both ventricles were dilated. The apex was thinned by a fresh infarction and mural thrombi were attached to the apical endocardium of the left ventricle. The anterior descending branch of the left coronary artery was occluded near its origin by a recent thrombus; the right coronary artery was almost completely obliterated by atheroma. Death

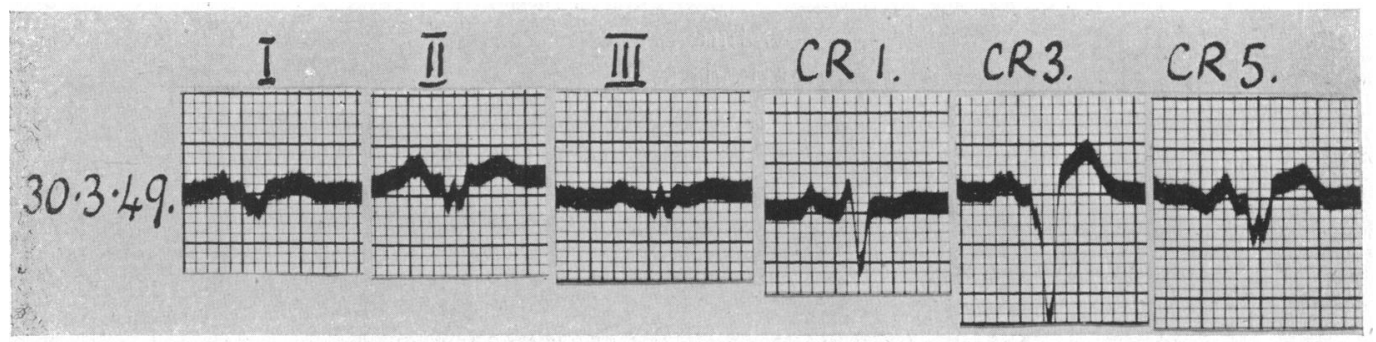

Fig. 1.-Case 1. Man, aged 66. Angina of effort for years, none for 3 months since in congestive heart failure. Admitted in acute pulmonary œdema, pyrexia $101^{\circ} \mathrm{F}$. Improved under treatment; died suddenly two days later. No cardiac pain while in hospital. Record shows absence of $R$ in I, II, CR3 and CR5; wide QS, dome-shaped R-T elevation in I, suggesting acute anterior infarction. For necropsy findings see text.

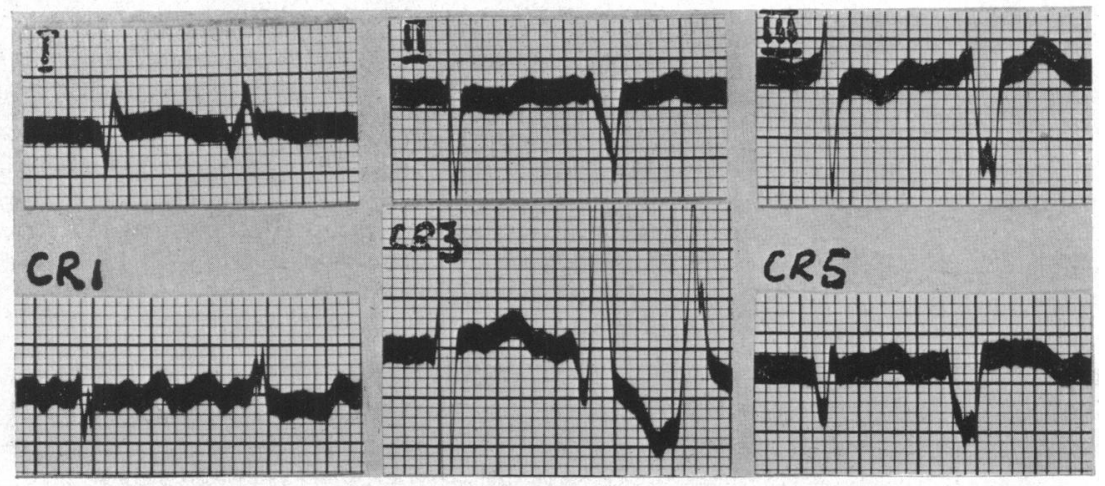

FIG. 2.-Case 2. Man, aged 56. Myocardial infarction twice, complicated by left femoral embolus, necessitating amputation of left leg after second attack in 1948. Admitted June, 1950, in congestive heart failure with pulmonary infarct. Died suddenly 6 days later in an attack of pulmonary œdema. No cardiac pain since last infarction. Record shows Q1, $Q$ in CR5 with minute $R$, but no $R-T$ displacement, suggesting old antero-apical scar. Auricular fibrillation. Coupling and sloping of R-T in II and III due to digitalis. For necropsy findings see text. 
was due to left ventricular failure caused by myocardial infarction through recent thrombosis in the anterior descending coronary artery.

The necropsy findings in Case 2 were similar. The heart was considerably enlarged, the right ventricle and atrium dilated. The anterior wall of the right ventricle was thinned to a thickness of 2-3 $\mathrm{mm}$. over an area about $4 \mathrm{~cm}$. in diameter, due to an old thrombosis in the anterior descending branch of the left coronary artery. An organized mural thrombus about $2 \mathrm{~cm}$. thick was adherent to the inner surface of the area of infarction. A recent thrombus was found in the posterior descending branch of the left coronary artery. There was an area of infarction $6 \mathrm{~cm}$. in diameter in the base of the right lung; no major pulmonary embolus was found in the main branches of the pulmonary artery.

While the diagnosis of acute infarction is evident in Case 1 from the electrocardiogram (Fig. 1) it is not so in Case 2. The record taken the day after admission and four days before death does not show signs of recent infarction (Fig. 2). Death was thought to be due to massive pulmonary embolism and the pathological diagnosis of a recent coronary thrombosis came as a surprise. Thus in acute pulmonary odema recent coronary thrombosis should be suspected as the cause and confirmation sought by frequent electrocardiographic recordings.

Case 3 had a slight subepicardial infarction which was enough to produce left ventricular failure in a heart overtaxed by hypertension. The electrocardiogram (Fig. 3) shows the pattern described in slight coronary attacks (Papp and Shirley Smith, 1951) with the changes limited to the R-T period and the $T$ waves only. There was no shock, the fall of blood pressure was only short lived, and pyrexia was slight. He was the only one of the three who survived.

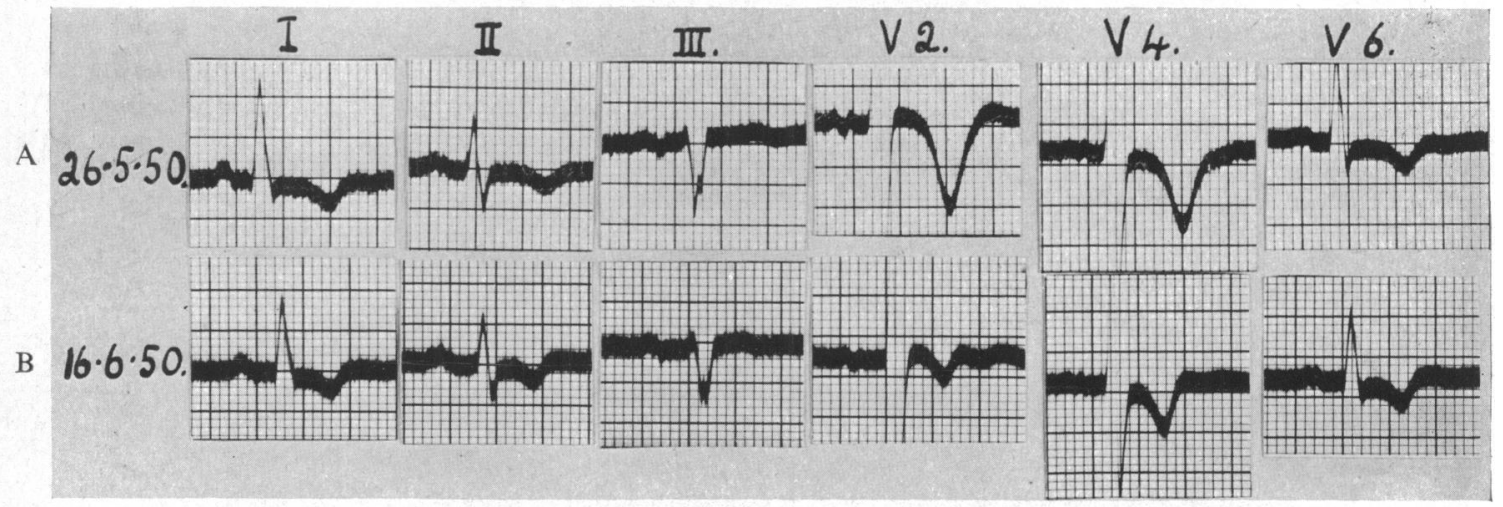

Fig. 3.- Case 3. Man, aged 61. During discussion, sudden attack of breathlessness. Admitted from Casualty with pulmonary œema and left ventricular failure; B.P. 230/140. Next day improved, B.P. 130/80; after 3 days B.P. 160/100. Slight pyrexia for 5 days. Uneventful recovery, never any chest pain. (A) Record on admission shows symmetrical, deeply inverted $T$ waves, coving of $R-T$ period in $V 2$ and $V 4$, suggesting subepicardial infarction. (B) 14 days later regression of signs. Shortening of R-T period due to digitalis.

The absence of pain in coronary occlusion during ischæmic heart failure has been explained by gradual narrowing of the artery through fibrosis, as opposed to sudden occlusion by thrombosis in cardiac infarction with pain (Gorham and Martin, 1938). An alternative explanation offered by Boyd and Werblow (1937) is that the infarction occurs into a dead area where nerves and vessels are destroyed by previous ischæmia. Neither of these theories can be applied to our cases where a fresh infarct was produced in a previously undamaged myocardial area. The explanation may be much simpler; acute respiratory distress and severe anginal pain can hardly exist side by side. The sufferance of severe orthopnœea accompanied as it always is, by feelings of tightness in the chest, overshadows the actual pain of cardiac ischæmia, as cardiac pain often overshadows the feeling of palpitation when ectopic tachycardia arises during coronary attacks. It 
seems to be more a question of perception than of existent anatomical conditions that the sensation of air-hunger, the most important for maintenance of life, prevails over the less important sensation of cardiac pain. In another 12 patients with congestive heart failure where a recent coronary thrombosis did not produce respiratory distress pain was always 'present.

\section{Acute Cardiac Infarction Without Pain in the Presence of COMPLETE HEART Block (5 cases)}

The absence of pain in coronary thrombosis accompanied by complete heart block is generally ascribed to Stokes Adams syndrome; this " completely masks the other features of the occlusion such as pain" (Master et al., 1938). White (1944) considered that the slight clinical disturbance accompanying coronary thrombosis with heart block was due to the smallness of the vessels supplying the A-V node. This argument can be easily refuted. Our Cases, 4, 6, and 7 had extensive infarctions as proved by the electrocardiogram (Fig. 4, 6, and 7) and the accompanying clinical syndrome (Table I), yet pain was absent. Case 8 had a posterior infarction with complete heart block and without pain in 1931 (Fig. 8), yet a small infarction without heart block in 1949 (Fig. 9) was accompanied by severe pain. Slight coronary attacks in absence of heart failure are always painful (Papp and Shirley Smith, 1951) and the extension of infarction can hardly be employed as a measure for pain.

Evidently the absence of pain is intimately connected with the sudden appearance of complete heart block. If complete heart block is present for a long time the heart is able to compensate for the bradycardia with an increase in stroke volume and in blood pressure. If it arises suddenly as during cardiac infarction, the compensatory mechanism cannot come into play because of the

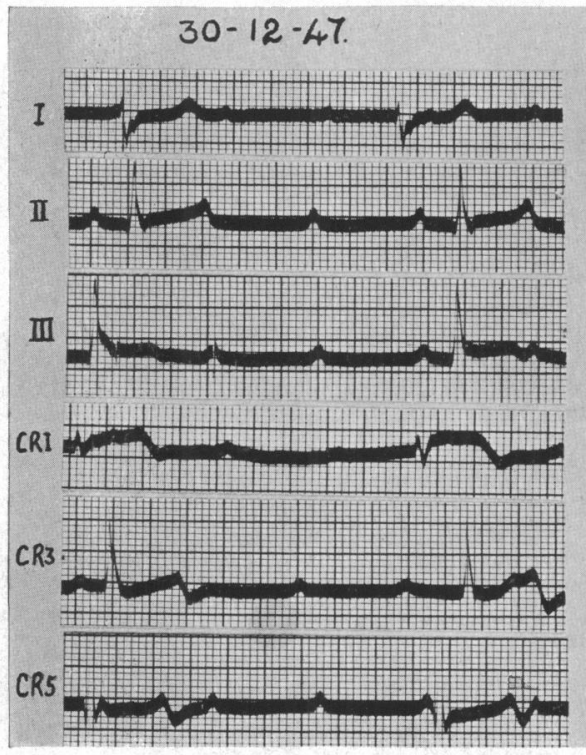

A

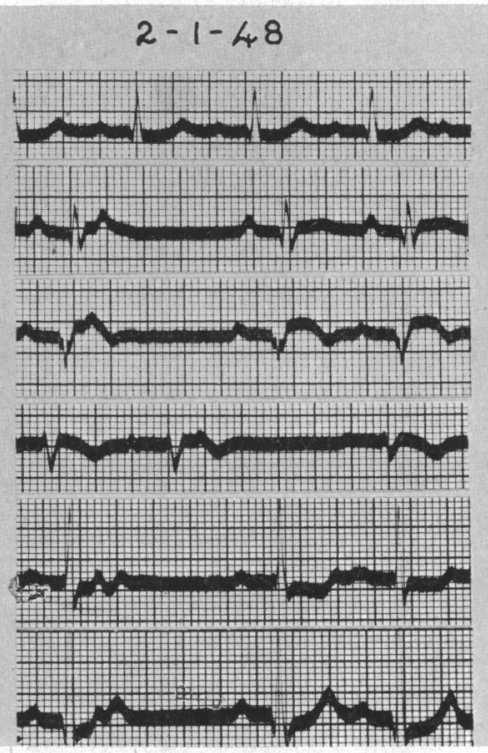

B

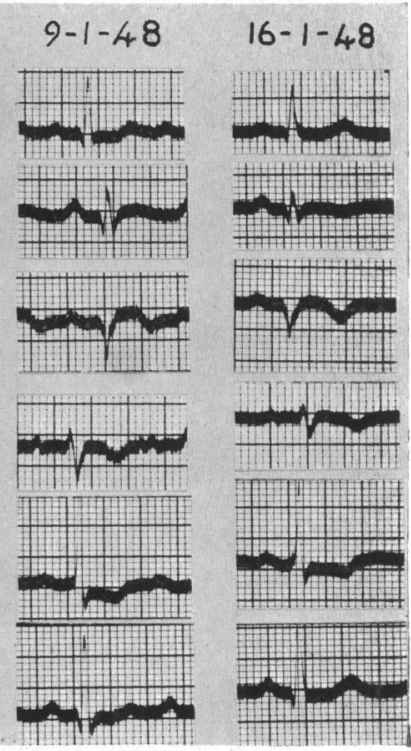

D

Fig. 4.-Case 4. Man, aged 58. While working as a composer, felt sick, vomited repeatedly, and dropped down without losing consciousness. On admission at $10 \mathrm{a} . \mathrm{m}$. looked shocked, but was fully conscious; pulse 100, regular, B.P. 60/30. At 3 p.m. rate suddenly fell to 36 , at 7.30 p.m. suddenly rose to 80 and remained at a normal level all the time. Pyrexia for 3 days, W.B.C.'s 13,000. Uneventful recovery with normal clinical and radiological heart findings at discharge. Never any cardiac pain. Records show (A) Complete heart block with simultaneous anteroposterior infarction; small RS in V1 with dome-shaped and elevated R-T; R-T elevation in LII and IIII with monophasic T waves. (B) P-R 0.24 sec., blocked auricular extrasystoles. (C) and (D) P-R normal, usual regressive changes. 


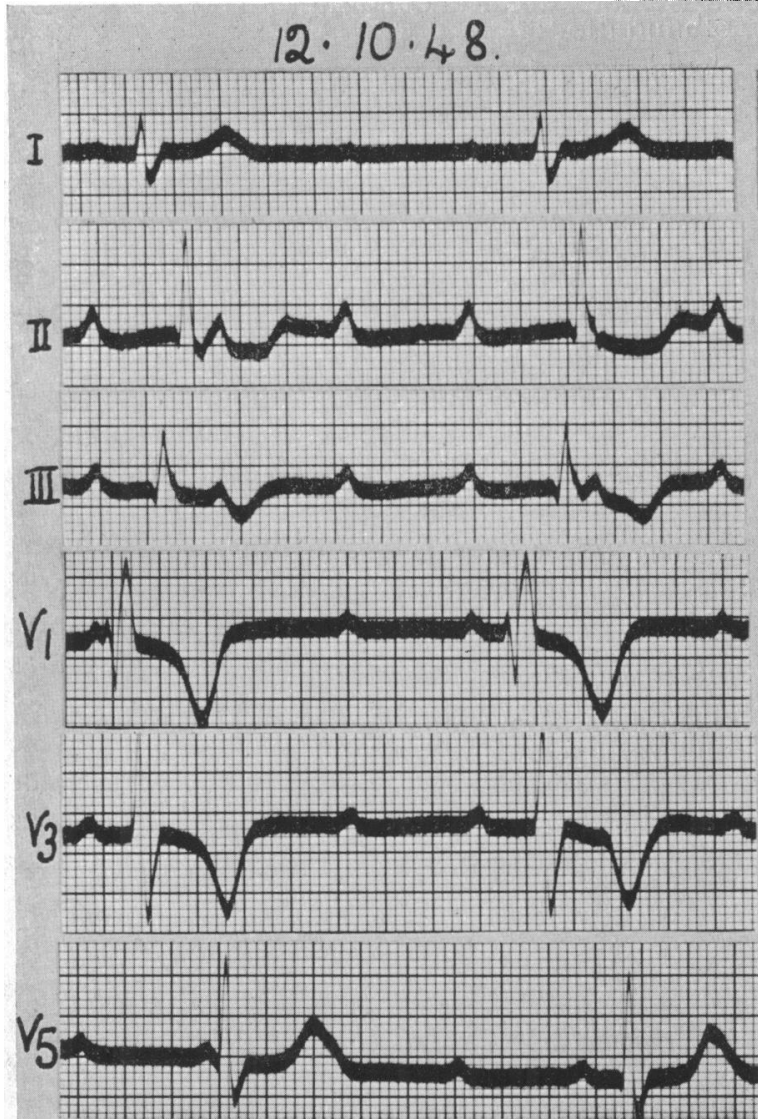

A

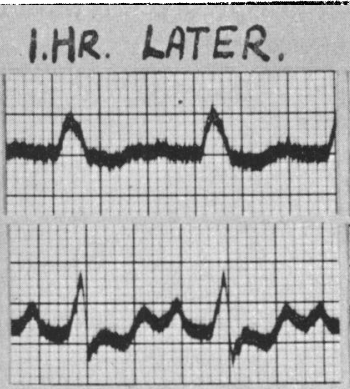
13. $10 \cdot 48$
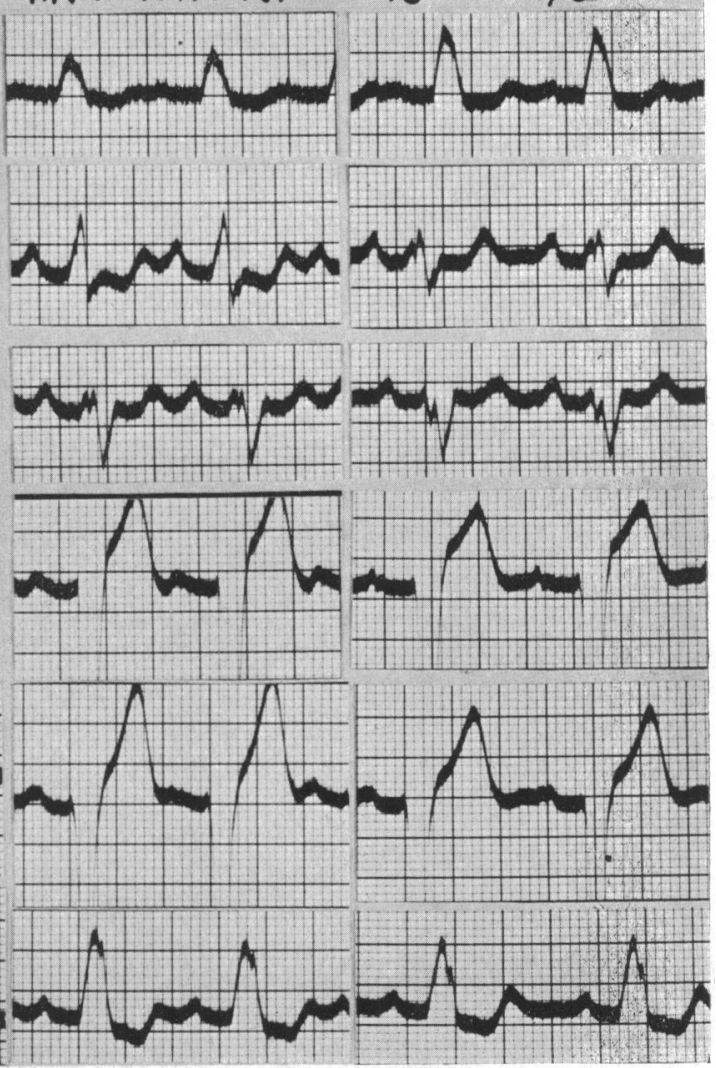

B

C

Fig. 5. - Case 5. Man, aged 67. Felt giddy on the road, perspired, vomited, and lost consciousness. On admission looked pale, but was conscious; no discomfort or pain in chest or arms on this or any past occasion. Pulse 38, regular; B.P. 150/120. One hour later, rate rose to 100 and remained 80-100. No pyrexia, W.B.C. 12,000. After few days B.P. 195/95. On discharge, 4 weeks later, no cardiac signs except for left ventricular hypertrophy consistent with hypertension. Records show (A) Complete heart block, right bundle branch block with anteroseptal infarction; deep inversion of T in V1 and V3. (B) Left bundle branch block with R-T depression in LII. (C) Left bundle branch block with different QRS pattern in LII, the permanent feature.

simultaneous fall of blood pressure, and syncope or Stokes Adams attacks may develop with a ventricular rate of 30-40 (see Cookson, 1942). Thus ventricular standstill and ventricular fibrillation, the essential features of Stokes Adams attacks (Parkinson et al., 1941), may be absent.

The syncopal attacks differed in our series from Stokes Adams seizures in another important respect: in four out of five patients there was no loss of consciousness (Table I). In fact Cases 4, 6,7 , and 8 were able to give detailed accounts of what happened while they " fainted." Evidently neither of them had complete cerebral anoxæmia. Haldane and Priestley(1935)in studying gradually increasing cerebral anoxæmia describe the symptoms as follows: "Power of memory is affected early. ... Muscular co-ordination is also affected so that a man cannot walk straight. . . . With further increase in the anoxæmia, power over the limbs is lost; the legs being first paralysed, then the arms and finally the head. The senses are lost one by one, hearing being apparently the last to go. The sense of pain seems to be lost early and to return late during recovery from the anoxamia."* All these symptoms were present in our series; Case 4, though apparently fully conscious during the

* Our italics. 


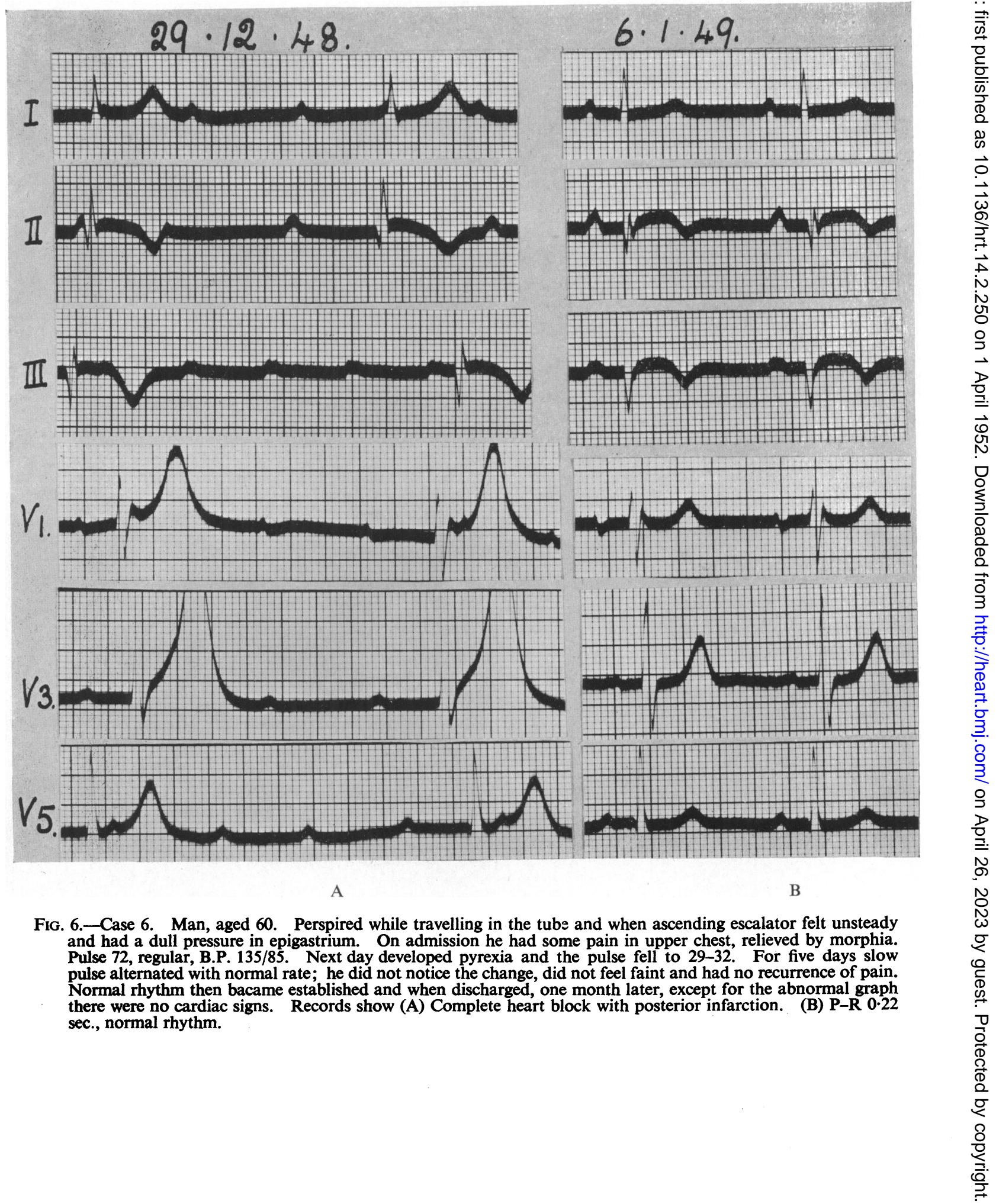




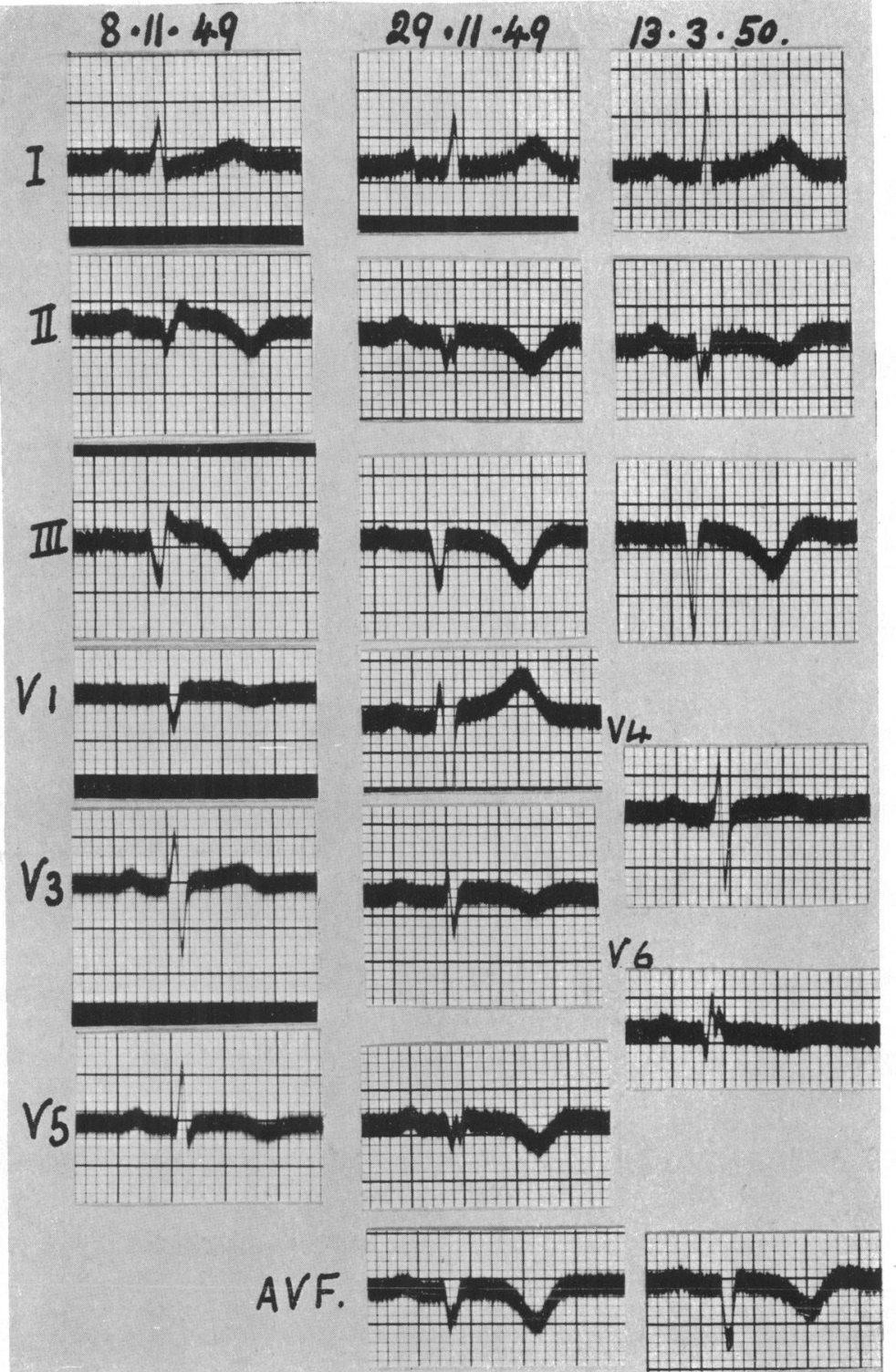

A

B

$\mathrm{C}$

FIG. 7.-Case 7. Spinster, aged 53. Had thyroidectomy for toxic goitre 8 years previously. While going to work in the morning felt faint, dropped down, was weak and helpless and short of breath, but never unconscious. On admission she looked pale and shocked, denied ever having had pain in chest, oppression, or indigestion; she gave a coherent account of what happened. Pulse 40, regular; B.P. 75/?. No E.C. was recorded. After $1 \frac{1}{2}$ hours rate became normal and remained so during 7 weeks of hospital observation. Pyrexia for two days, W.B.C.'s 11,000 , B.S.R. $100 \mathrm{~mm}$. B.P. 80/60-95/60 for a fortnight, $110 / 70$ at discharge. Uneventful recovery with anticoagulant treatment. Never any cardiac pain or oppression. Cardioscopy showed moderate enlargement of the heart; there was no failure. Four months later she was back at light work and had no symptoms. Records show (A) Extensive posterior infarction; absent $\mathbf{R}$ and slight $\mathrm{T}$ inversion in V1 suggests simultaneous anteroseptal ischæmia. Normal rhythm 24 hours after clinical heart block. (B) V1 now normal; QRS changes in V5 suggest lateral extension. (C) Usual regressive changes. 
TABLE I

Clinical Features in Cardiac Infarction with Complete Heart Block

\begin{tabular}{|c|c|c|c|c|c|c|c|c|}
\hline \multirow[b]{2}{*}{ Case No. } & \multirow{2}{*}{$\begin{array}{l}\text { Age and } \\
\text { Sex }\end{array}$} & \multirow[b]{2}{*}{ Attack } & \multirow[b]{2}{*}{ Unconsc. } & \multirow[b]{2}{*}{ Pulse rate } & \multicolumn{2}{|c|}{ Blood pressure } & \multirow[b]{2}{*}{ Pyrexia } & \multirow[b]{2}{*}{ W.B.C's } \\
\hline & & & & & adm. & disch. & & \\
\hline $\begin{array}{l}4 \\
5 \\
6\end{array}$ & $\begin{array}{l}58, \mathrm{M} . \\
67, \mathrm{M} . \\
60, \mathrm{M} .\end{array}$ & $\begin{array}{l}\text { Faint and vomiting } \\
\text { Giddy and vomiting } \\
\text { Faint and unsteady }\end{array}$ & \pm & $\begin{array}{c}36 \\
38 \\
100 * \text { on adm. } \\
32 \text { next day }\end{array}$ & $\begin{array}{l}60 / 30 \\
150 / 120 \\
135 / 85\end{array}$ & $\begin{array}{l}130 / 80 \\
195 / 95 \\
140 / 75\end{array}$ & $\begin{array}{l}3 \text { days } \\
2 \overline{\text { days }}\end{array}$ & $\begin{array}{c}13,000 \\
12,000 \\
?\end{array}$ \\
\hline $\begin{array}{l}7 \\
8\end{array}$ & $\begin{array}{l}53, \mathrm{~F} \\
41, \mathrm{M} .\end{array}$ & $\begin{array}{l}\text { Faint and weak } \\
\text { Dyspnœa }\end{array}$ & $\overline{-}$ & $\begin{array}{l}40 \\
42 * *\end{array}$ & $\begin{array}{r}80 / 60 \\
135 / 90\end{array}$ & $\begin{array}{l}110 / 70 \\
140 / 90\end{array}$ & $\begin{array}{c}2 \text { days } \\
?\end{array}$ & $\begin{array}{c}11,000 \\
?\end{array}$ \\
\hline
\end{tabular}

*Pain on admission.

** Seen three days after attack.

faint, did not remember details; Case 6 felt " like drunk" when ascending the escalator; Case 7 felt "weak and helpless as though she had no strength to move" and except for Case 6, pain was absent in all. Pain in this patient began when he was in normal rhythm and had a normal blood pressure, but was absent during the attack and later when he had complete heart block. StokesAdams syndrome is therefore not the only syndrome of cerebral anoxæmia caused by cardiac conditions. The combination of sudden bradycardia with fall of blood pressure, as it occurs in coronary thrombosis accompanied by complete heart block, causes partial cerebral anoxæmia with depression of the sensory centres and thus suppresses cardiac pain. If heart block is intermittent and normal rhythm is restored before acute cardiac ischæmia is over there may be some pain; this again disappears when complete heart block sets in.

The electrocardiographic features are summarized in Table II. Complete heart block was of early appearance and transient in all. When it lasted for hours only, the transition was sudden and the successive electrocardiograms showed stable normal rhythm (Fig. 4, 5, and 7). When it lasted for days (Fig. 6) or weeks (Fig. 8) there was alternation between block and sinus rhythm and the reversion to normal was gradual through a period of latent heart block which may have been present for weeks (Case 8). Associated right bundle branch block was present in two cases (Fig. 5 and 8). It was temporary in both; in one the ventricular complexes became normal (Case 8) in the other (Case 5) they reverted to left bundle branch block which became the permanent electrocardiographic feature. Posterior infarction was present in three; in Case 5 (Fig. 5) there was an anteroseptal pattern and in Case 4 (Fig. 4) the præcordial leads showed anteroseptal and the limb leads posterior patterns; some signs of anteroseptal ischæmia were present in Case 7 (Fig. 7) as well. The frequency of posterior infarction in association with complete heart block has been frequently emphasized since the artery of the node, in 92 per cent of all hearts, derives from the right coronary artery. The simultaneous association of anterior with posterior patterns in septal infarction was described by Roesler and Dressler (1947) who found this pattern in 5 cases with necropsy

TABLE II

Electrocardiographic features in Cardiac Infarction with Complete Heart Block

\begin{tabular}{|c|c|c|c|c|}
\hline Case No. & C.H.B. duration & $\mathbf{P}-\mathbf{R}+$ & B.B.Bl. & Infarction \\
\hline $\begin{array}{l}4 \\
5 \\
6 \\
7 \\
8\end{array}$ & $\begin{array}{l}4 \text { hours } \\
1 \text { hour } \\
5 \text { days and off } \\
1 \frac{1}{2} \text { hours }(?)^{*} \\
7 \text { days }+\end{array}$ & $\begin{array}{l}\overline{0.22} \\
0.22 \\
\overline{0.34^{* *}} \\
0.26 \dagger\end{array}$ & $\begin{array}{l}\text { R.; next day } L . \\
\overline{-} \\
\text { R., later } \\
\text { normal }\end{array}$ & $\begin{array}{l}\text { ant.-post. } \\
\text { ant.-sept. } \\
\text { post. } \\
\text { post-lat. } \\
\text { post. }\end{array}$ \\
\hline
\end{tabular}

C.H.B.=complete heart block; B.B.Bl.=bundle branch block; R.=right; L. $=$ left. ${ }^{*}$ No E.C. ${ }^{* *}$ After four weeks. † After ten weeks. 


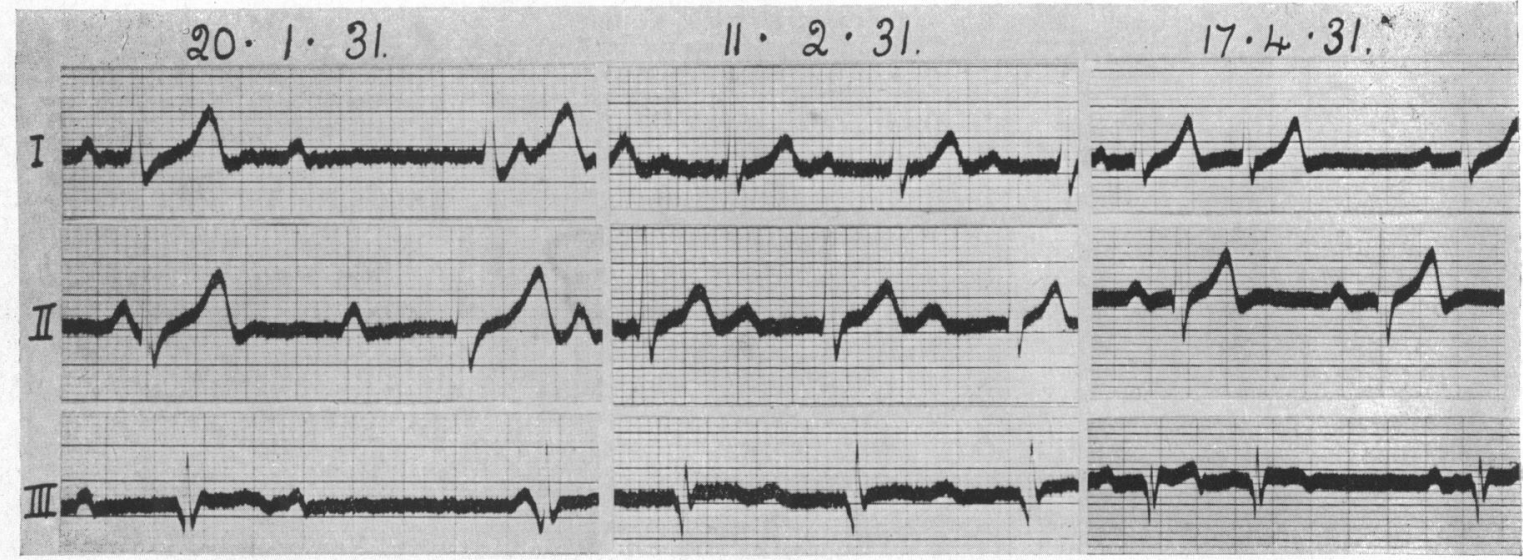

A

B

C

Fig. 8.-Case 8. Man, aged 41. Obese, no previous medical history. Seen in consultation by Dr. K. Shirley Smith in Jan., 1931. Few days previously attack of sudden dyspnœea while climbing two flights of stairs; felt faint, looked pale, but did not lose consciousness. Bradycardia since. Never any chest pain. Pulse 42-48, at times irregular, B.P. 135/90, normal heart. Rate became normal after one week; three months later he was well. Records show (A) Complete heart block with right bundle branch block (QRS 0.11). (B) P-R 0.36 sec.; QRS normal. Q3 and bowing of R-TIII suggest posterior infarction. (C) P-R 0.26 sec.; auricular extrasystoles W complexes in LIII.
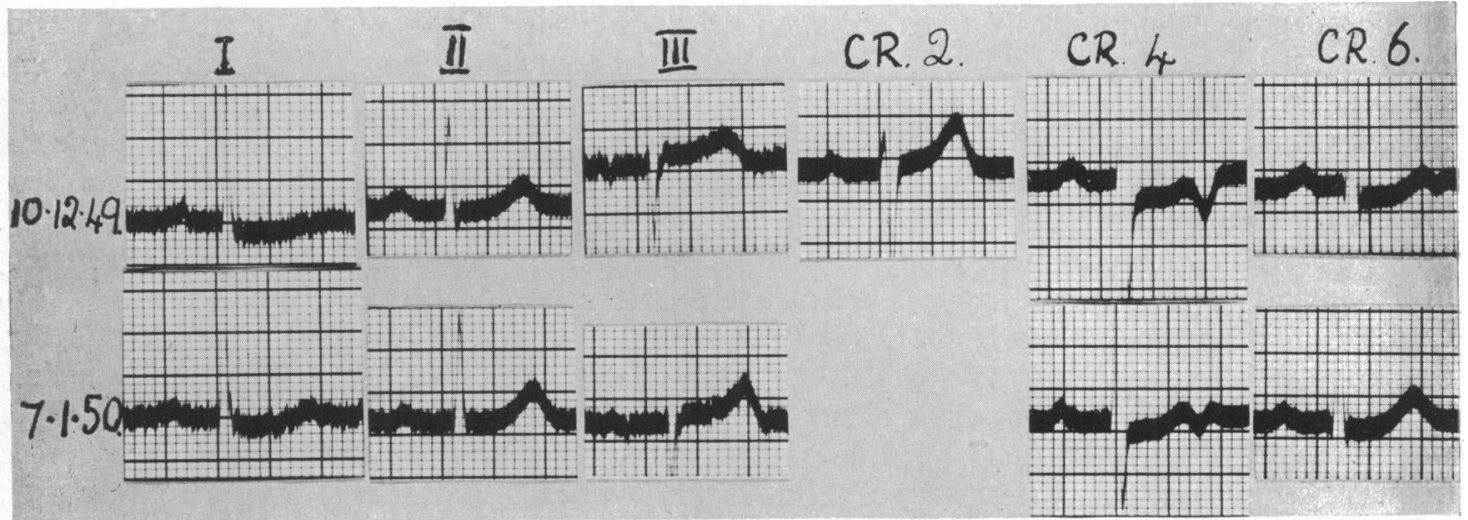

Fig. 9.-Case 8. Eighteen years later, one waek after prolonged coronary pain followed by angina of effort.

(A) Anterolateral subepicardial infarction, normal rhythm. (B) Restoration towards normal.

control. Though heart block was transient in our series, there are strong arguments suggesting that permanent heart block and bundle branch block may arise through a similar mechanism. Out of a series of 117 cases with atrioventricular block only 12 per cent had " clinical" myocardial infarction and only 9 per cent suffered from angina pectoris (White, 1944). Since atrioventricular block is mainly an arteriosclerotic disease the suspicion is well founded that the first syncopal attack in the life of many of these patients may be an unnoticed cardiac infarction without pain.

The favourable outcome in our series contrasts with the grave prognosis generally given. This may be only partly explained by the lower ages; the average age of our cases was 57 as contrasted with 60 in those of Master et al. (1938) and with Cookson's (1942) series where five out of ten patients were over 70. Complete heart block in cardiac infarction may not necessarily mean severe septal necrosis and consequent interruption of the bundle or severe damage to the A-V node. In fact 
in 14 cases of Myers et al. (1949), with extensive infarction of the posterobasal part of the intraventricular septum, not one had atrioventricular block. Transitory oedema or ischæmia of both bundle branches or of the Purkinje fibres in the lower part of the septum may cause complete heart block without interference to the vital structure of the node or the bundle. The transformation from complete heart block and right bundle branch block into sinus rhythm and left bundle branch block in Case 5, may be so explained (Littman, 1949). A lesion to the bundle or the node may also be repaired under favourable circumstances by the existing septal anastomotic channels (Laubry et al., 1948). The ultimate prognosis therefore depends on the extent of the infarction; whether this is large (Cases 4, 6, and 7) or small (Case 8), complete heart block will be only a symptom in either event.

\section{SUMMARY}

Complete absence of pain during acute cardiac infarction was observed in 7 out of 150 cases (4.6\%). Slight pain was present in an eighth case also included in the series.

Three patients had congestive heart failure with cardiac infarction. Two died and at necropsy were found to have extensive arteriosclerotic heart disease with occlusion of more than one main coronary artery. The third who survived had a slight cardiac infarction during an attack of cardiac asthma. Acute paroxysmal dyspncea was the main symptom in all; it is thought this may overshadow coronary pain and thus explain its absence in the severely ill. In another 12 patients with pre-existing congestive heart failure, in whom recent coronary occlusion did not produce acute respiratory distress, pain was present.

Five patients had complete heart block during the attack and these were the only ones with complete heart block in the series (3.3\%). In four there was complete absence of pain; in the fifth who had intermittent heart block pain appeared when he reverted to normal rhythm during the attack. Complete heart block was recorded in four; it was transient in all and lasted from one and a half hours to one week or more. In one patient no record was obtained during the hour while the pulse rate was 40 . The electrocardiogram showed posterior infarction in three, anteroseptal infarction with right bundle branch block and later left bundle branch block in one, and anteroposterior infarction in one. All patients recovered; Case 8 had a small anterolateral infarction accompanied by pain, but not by heart block, 18 years later, from which also he recovered. Faintness with a pulse rate of $30-40$ was the main clinical symptom, but, complete loss of consciousness occurred only in one patient. These attacks differ from classical Stokes-Adams attacks in so far as ventricular standstill, ventricular tachycardia, and therefore complete loss of consciousness may be absent. Sudden fall of pulse rate accompanied by fall of blood pressure, as it occurs in complete heart block during acute cardiac infarction, may induce incomplete cerebral anoxæmia only; this causes faintness without loss of consciousness, but with loss of sense of pain. The difference as opposed to classical Stokes-Adams attacks lies in the different mechanism causing a lesser degree of cerebral anoxæmia.

Prognosis in cardiac infarction without pain and complicating heart failure is serious. With complete heart block it may be less severe than is generally accepted since transient block may be a sign of only temporary ischæmia of the conducting system.

I wich to thank the Physicians of the Charing Cross Hospital for permission to make use of patients under their care, Dr. K. Shirley Smith for the private notes on Case 8, and Miss Anne Smith, cardiographic technician to the hospital, for electrocardiography and mounting. 


\section{REFERENCES}

Boyd, L. J., and Werblow, S. C. (1937). Amer. J. med. Sci., 194, 814. Cookson, H. (1942). Brit. Heart J., 4, 163.

East, C. F. T., Bain, C. W. C., and Cary, F. L. (1928). Lancet, 2, 60.

Gorham, L. W., and Martin, S. J. (1938). Arch. intern. Med., 62, 821.

Haldane, J. S., and Priestley, J. G. (1935). Respiration. Oxford.

Kennedy, J. A. (1937). Amer. Heart J., 14, 703.

Kerr, J. D. O. (1937). Lancet, 2, 1066.

Littman, B. (1949). New Eng. J. Med., 241, 89.

Laubry, C., Souliê, P., and Thys, H. (1948). Arch. Mal. Couur, 41, 1.

Master, A. M., Dack, S., and Jaffe, H, L. (1938). Amer. J. med. Sci., 196, 513.

Myers, G. B., Klein, H. A., and Hiratzka, T. (1949). Amer. Heart J., 37, 720.

Papp, C. (1934). Cuore e Circol., 18, 565.

-, and Shirley Smith, K. (1951). Brit. Heart J., 13, 17.

Parkinson, J., and Bedford, D. E. (1928). Lancet, 1, 4.

—, Papp, C., and Evans, W. (1941). Brit. Heart J., 3, 171.

Roesler, H., and Dressler, W. (1947). Amer. Heart J., 34, 817.

White, P. D. (1944). Heart Disease. 3rd edition. New York. 